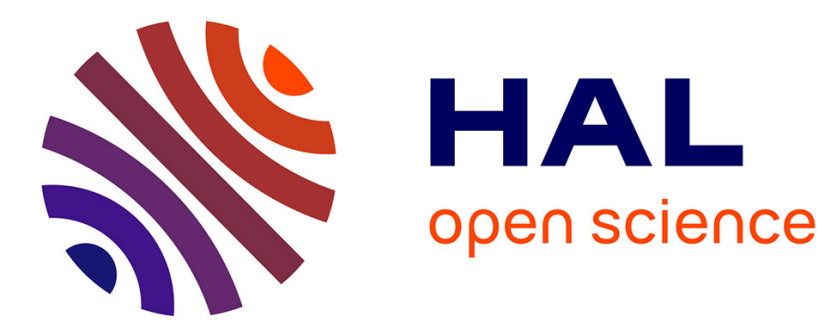

\title{
SEIG-based wind turbine condition monitoring using stray flux instantaneous frequency estimation
}

Mohamed Salah, Khmais Bacha, Abdelkader Chaari, Mohamed Benbouzid

\section{To cite this version:}

Mohamed Salah, Khmais Bacha, Abdelkader Chaari, Mohamed Benbouzid. SEIG-based wind turbine condition monitoring using stray flux instantaneous frequency estimation. IEEE ISIE 2015, IEEE, Jun 2015, Buzios, Brazil. pp.861-866, 10.1109/ISIE.2015.7281583 . hal-01213110

\author{
HAL Id: hal-01213110 \\ https://hal.science/hal-01213110
}

Submitted on 7 Oct 2015

HAL is a multi-disciplinary open access archive for the deposit and dissemination of scientific research documents, whether they are published or not. The documents may come from teaching and research institutions in France or abroad, or from public or private research centers.
L'archive ouverte pluridisciplinaire HAL, est destinée au dépôt et à la diffusion de documents scientifiques de niveau recherche, publiés ou non, émanant des établissements d'enseignement et de recherche français ou étrangers, des laboratoires publics ou privés. 


\section{SEIG-based Wind Turbine Condition Monitoring using Stray Flux Instantaneous Frequency Estimation}

\author{
Mohamed Salah, Khmais Bacha, Abdelkader Chaari \\ National Engineering High School of Tunis, Tunisia \\ Unit of Research in Control, Monit. and Reliab. of the Sys. \\ Mohamed.salah.isetgf@gmail.com
}

\author{
Mohamed Benbouzid \\ University of Brest \\ EA 4325 LBMS, Brest, France \\ Mohamed.Benbouzid@univ-brest.fr
}

\begin{abstract}
For economic and environmental reasons, wind turbines are becoming a potential renewable power source that could replace conventional fossil-fuelled plants. In remote areas where the power grid is unavailable, these wind plants may be equipped with self-excited induction generators. Order to maximize their productivity, the generators condition has to be continually monitored. For this purpose, many processing techniques have been interested to the analysis of fluently known signals such that vibration, ultrasound, acoustic emission, temperature, electrical amounts, etc. In this work, we present an innovative approach for monitoring the drive speed of such generator. The proposed technique is based on estimation of the instantaneous frequency related to the signal stemming from a stray flux sensor. Experimental investigations conducted on a laboratory test-rig have shown promising results in terms of speed monitoring by the employ of a low-cost sensor.
\end{abstract}

Keywords-Condition monitoring, estimation, self-excited induction generator, speed tracking, stray flux, wind turbine.

\section{INTRODUCTION}

Most small plants implemented in remote areas harness the wind energy for electricity generation. For reducing operational and maintenance costs, health assessment of all the energy conversion subsystems (ECS) has become a challenge research task. The reduction of downtime requires a particular attention for developing innovative techniques efficient for real-time monitoring of the whole arrangement.

Since they are situated on extremely high towers, the critical ECS components (blades, drive trains, and generators) are hardly accessible. This fact further complicates the diagnosis operation when a failure occurs.

For wind energy applications, synchronous generators may be used. To overcome the need of an external power supply for producing the magnetic excitation field, permanent magnet generators are preferred. However, by the use of these machines the output voltage level is strongly tied to the prime mover speed. In fact, owing to their operating principle, the generated voltage increases quasi-linearly with the turbine speed [1].

Because of their many advantageous features over synchronous generators, the use of induction machines as generators is becoming more and more popular. In fact, these machines are characterized by their reduced maintenance cost and their robustness since their rotors are brushless. Furthermore, due to the saturation phenomenon, these generators are able to cope with a small increase in speed from their rated value. Yet, their major drawback is the poor voltage regulation under varying speed. However, thanks to the development of static power converters the control of the output voltage of induction generators has become more flexible [2].

Unlike grid-connected induction generators, voltage and frequency of a self-excited generator (SEIG) are not constant, and this makes their condition monitoring (CM) much more difficult. Though, with such configuration the voltage collapses under condition of short-circuited terminals and offers an important self-protection against severe overloads.

Gearboxes have been classified as major cause of turbine failure. Yet, data quantitative analysis related to failure rate trends of wind turbines has shown that most defects were linked to the electric system followed by sensors and blades/pitch components [3]. For CM of the drive train (bearing, gears, etc.) of wind ECS, main conventional techniques have focused on the data analysis stemming from sensors of vibration, temperature, speed, and output torque. Later than, other works have interested to the supervision of useful outputs across the generator terminals (voltage, current, power, power factor [4], etc.). A review of the different maintenance strategies, CM and diagnosis techniques has been detailed in [3-5].

In this work we are going to propose an instantaneous frequency (IF) based approach for monitoring the drive speed of a SEIG without needing to implement mechanical sensors or access the generator terminals.

\section{THEORETICAL BACKGROUND}

\section{A. Wind Turbine's Power}

Obviously, the wind is due to the motion of air mass $m$ at a speed $V_{W}$. This displacement gives rise to a kinetic energy $E_{i}$ expressed by

$$
E_{i}=m V_{W}^{2} / 2
$$


By considering the air density $\rho$, the air mass passing perpendicularly through a given area $S$ during a time $t$ may be written by

$$
m=\rho S V_{W} t
$$

Taking into account the previous relations, the maximum wind power incident on the rotor area of a turbine with pales of radius $r$ will be given by

$$
P_{i}=\rho \pi r^{2} V_{W}^{3} / 2 .
$$

Depending on the turbine technology, the ratio $\lambda$ of its angular speed $\omega_{t}$ at the tip of a blade (radius $r$ ) to the free stream wind speed $V_{W}$ is given by [6]

$$
\lambda=\omega_{t} r / V_{W} .
$$

Evidently, the wind turbine cannot convert the totality of the incident power $P_{i}$. In fact it is characterized by a power coefficient $C_{P}$ that depends on the tip speed ratio $\lambda$. Hence, the mechanical turbine power $P_{t}$ captured from the wind will be given by

$$
P_{t}=\rho \pi C_{P}(\lambda) r^{2} V_{W}^{3} / 2 .
$$

A typical variation of the power coefficient [6] is shown by Fig. 1. Order to extract the maximum available power at any wind velocity, the turbine speed has to be adjusted such that the tip speed ratio equals the value $\lambda_{\text {opt }}$.

Taking into account the step-up speed ratio $(x)$ of the gearbox, the optimal generator speed will be given by

$$
\Omega_{r}^{o p t}=x \lambda_{o p t} V_{W} / r \text {. }
$$

\section{B. Induction Generators}

Induction machines are initially intended to operate as motors by developing an electromagnetic torque $T_{e}$ that may be expressed in the d-q frame by

$$
T_{e}=3 X_{m}\left(I_{r d} I_{s q}-I_{r q} I_{s d}\right) /\left(2 \Omega_{s}\right) .
$$

Where $\Omega_{s}$ is the machine's synchronous speed, $X_{m}$ the magnetizing reactance, $I_{s}$ and $I_{r}$ are respectively the stator and rotor currents.

Given the per phase equivalent circuit (Fig. 2.a), under steady state condition $T_{e}$ may be expressed by

$$
T_{e}(s)=k \cdot s /\left(a_{2} s^{2}+a_{1} s+a_{0}\right) .
$$

Where the parameters $k, a_{2}, a_{1}$, and $a_{0}$ are detailed in [7], and $s$ denotes the slip factor.

Since the stator and rotor reactances may be neglected compared to $X_{m}$, Eq. (8) shows that $\operatorname{sgn}\left(T_{e}\right)=\operatorname{sgn}(s)$.

Hence, by exceeding the synchronous speed $\Omega_{s}$ (negative slip), the electromagnetic torque changes its sign and the machine may be operated into generator mode.

Let us note $\alpha_{M}$ the lag angle of the stator current with respect to the induced voltage $\left(0<\alpha_{M}<\pi / 2\right)$ when the machine is operated into motor mode (positive slip). The change in the torque sign will force this lagging angle to exceed $\pi / 2$. In fact, as it can be easily shown by a classical circle diagram, we can write

$$
\alpha_{G}=\pi-\alpha_{M}>\pi / 2 .
$$

Thus, beyond the synchronous speed $\Omega_{s}$, the active current component $I_{s d}$ will be negative $\left(\cos \alpha_{G}=-\cos \alpha_{M}\right)$, and the active power will change of flow direction. Yet, the reactive component $I_{s q}$ will conserve its positive sign ( $\left.\sin \alpha_{G}=\sin \alpha_{M}\right)$, and the machine will always need to consummate reactive power.

Given the previous statements, to harness an induction machine in generator mode it is necessary to exceed its synchronous rotational speed and to provide reactive power for magnetizing its rotor. This reactive power may be called from the electricity network (grid connected mode) or provided by installing a local capacitor bank (SEIG mode). A per phase equivalent circuit of a SEIG [8] is given by Fig. $2 b$. However, under SEIG mode the machine cannot build an output voltage across its terminals unless a residual magnetism is already present in its rotor for initiating the process of selfexcitation.

\section{Hilbert Transform for IF estimation}

Given a one dimension real-valued signal $x(t)$, while the real part of its analytic representation $x_{a}(t)$ must be the original data sequence, its imaginary part may be provided by the Hilbert transform (HT) that results from the convolution product of $x(t)$ with the impulsion function $h(t)=1 /(\pi t)[9-$ 10]:

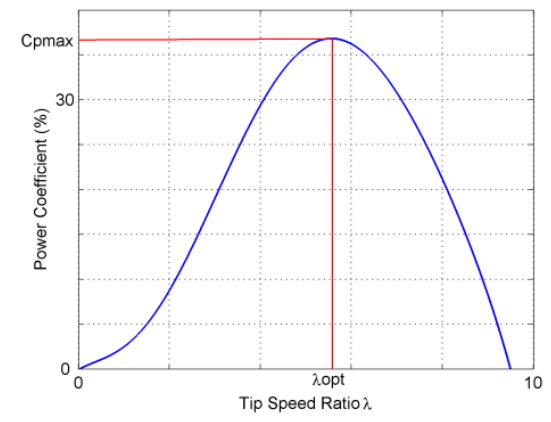

Fig. 1. Typical variation of power coefficient in wind turbine.

a

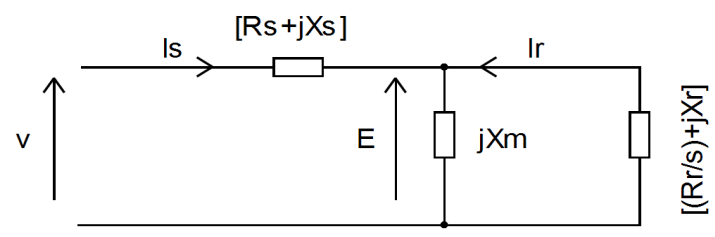

b

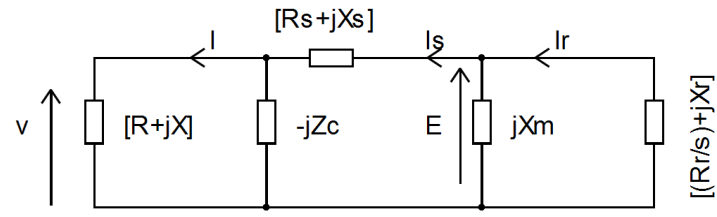

Fig. 2. Per phase equivalent circuit: (a) induction motor, (b) SEIG [8]. 


$$
H_{x}(t)=x(t)^{*} h(t)=\int_{-\infty}^{+\infty} x(\tau) /[\pi(t-\tau)] d \tau .
$$

It follows

$$
x_{a}(t)=x(t)+j H_{x}(t) .
$$

The application of Fourier transform to Eq.(11) gives

$$
X_{a}(f)=X(f)[1+\operatorname{sgn}(f)]
$$

As shown by the previous equation, $x_{a}(t)$ has the particularity to belong to the Hardy space. Indeed, its energy is totally concentrated into the positive spectrum part. It follows the convenience of such a representation for analysis of real causal processes without any loss of information. In fact, the original data may be simply recovered by retrieving the real part. On the other hand, the Euler's formula applied to Eq.(11) states:

$$
x_{a}(t)=A_{x}(t) e^{j \varphi_{x}(t)} .
$$

In order to avoid phase discontinuities at $\pm \pi$, a smoother time variation may be introduced by adding or subtracting an appropriate multiple of $2 \pi$ radians to the original angle $\varphi_{x}(t)$. Thus, an unwrapped phase version $\varphi_{x}^{u}(t)$ is obtained. Given $\varphi_{x}^{u}(t)$, the IF corresponds to the time derivative:

$$
I F_{x}(t)=d \varphi_{x}^{u}(t) /(2 \pi d t) .
$$

Because of unavoidable noise, all real-data signals issued by physical sensors cannot be monochromatic. Indeed, multifrequency components are conjointly present and it will be useful to decompose the original signal version into a set of nearly mono-component signals.

Thanks to the Hilbert-Huang transform, a given physical data set may be subjected to empirical mode decomposition to be represented by a finite collection of intrinsic mode functions [11-12]. Thereafter, the IF can be estimated through simple application of HT. However, despite its easy implementation, the HT approach may lose physical meaning of frequency in many signal cases. In addition, the numerical evaluation of derivatives is often unstable.

\section{Stray Flux Theory}

Since their initial manufacturing, electrical machines cannot be strictly perfect. Indeed, an inherent dissymmetry is always present.

Moreover, the relative permeability of its magnetic circuit is limited. Thereafter, this main pathway cannot channel the totality of the magnetic fluxes, and a portion will radiate outside of the machine's frame. This stray flux does not participate in the process of generating of useful outputs. However it has the particularity to provide useful information about the phenomena that occur inside the machine.

Indeed, when a fault occurs into stator or rotor windings, harmonics distribution into the air-gap will be altered. Consequently, the stray flux will certainly undergo these changes and may be of interest for monitoring purpose [13-15].

\section{Proposed Monitoring TechniQue}

The main idea of the proposed approach is based on the use of a circular coil for sensing a retrieved image of the stray flux (Fig. 3). This simple sensor will be placed such that its crosssection will be orthogonal to that of the machine (transversal position). The emf induced across the coil terminals is firstly conditioned thanks to a zero-phase digital filter (Table I: Filter A). Hence, the original data are processed in both the forward and reverse directions and the resulting data sequence will have precisely zero-phase distortion. Thus, start-up and ending transients are minimized by matching initial conditions. After that, by application of the HT we estimate the IF. A second low-pass filtering (Table I: Filter B) is then performed to obtain a smoothed version that is more legible for speed tracking. It should be noted that the parameters of the proposed filters are given just for guidance with respect to the specifications of the used sensor and the presented results.

TABLE I. SPECificAtions OF THE PROPOSED FILTERS

\begin{tabular}{lll}
\hline & \multicolumn{1}{c}{ Filter A } & \multicolumn{1}{c}{ Filter B } \\
\hline Type & Butterworth & Butterworth \\
\hline Order & 5 & 3 \\
\hline Cutoff frequency & $100 \mathrm{~Hz}$ & $5 \mathrm{~Hz}$ \\
\hline $\begin{array}{l}\text { Filtering } \\
\text { technique }\end{array}$ & $\begin{array}{l}\text { zero-phase digital } \\
\text { filtering }\end{array}$ & $\begin{array}{l}\text { zero-phase digital } \\
\text { filtering }\end{array}$ \\
\hline
\end{tabular}

\section{EXPERIMENTAL RESULTS}

The machine under investigation is a three-phase, $400 \mathrm{~V}$, $50 \mathrm{~Hz}, 1 \mathrm{~kW}$ four-pole induction generator. Its rotor is squirrel cage, cast aluminum type with 28 bars.

Order to secure a high starting torque with good speed control, the drive task has been entrusted to a $1 \mathrm{~kW}$, four-pole compound wound dc motor with $U_{n}=220 \mathrm{~V}, I_{n}=6.2 \mathrm{~A}, U_{e x n}$ $=200 \mathrm{~V}$, and $I_{e x n}=0.24 \mathrm{~A}$. For each conducted test (Fig. 4), we have acquired the time signals relating to the motor field current $I_{e x}$, the generator load current $i_{a}$, and the emf induced at the terminals of a search coil. While the load current have been picked-up by means of a clamp, the current $I_{e x}$ has been deducted from the voltage drop sensed at the terminals of a resistor $R_{m}$ inserted in series with the motor shunt winding.

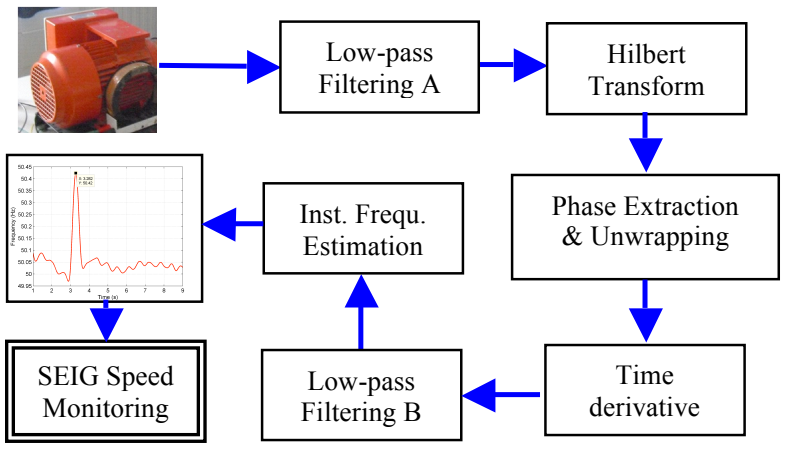

Fig. 3. Proposed monitoring approach. 


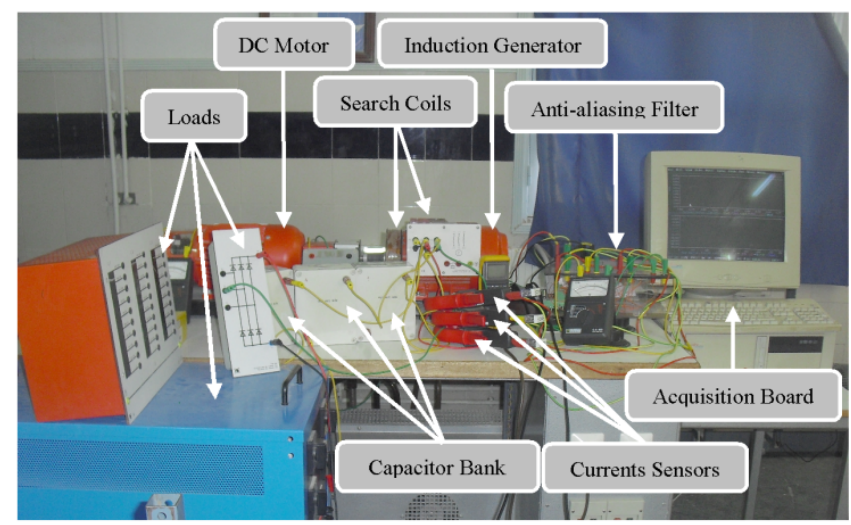

Fig. 4. Laboratory test rig.

Before being connected to a 12-bit data acquisition board, these signals have been conditioned thanks to an anti-aliasing filter (cutoff frequency $=1 \mathrm{kHz}$ ). The sampling frequency has been fixed to $5 \mathrm{kHz}$, and the further signal processing has been achieved using MATLAB software.

Given the resistance of the shunt winding $R_{s h}=582 \Omega$, the measuring resistance $R_{m}=2 \Omega$, and the excitation voltage $U_{e x}=$ $200 \mathrm{~V}$, an adjustable resistance $R_{0}$ has been inserted into the motor exciter circuit in order to set the generator output frequency at $f_{s}=50 \mathrm{~Hz}$.

For the no-load condition, $R_{0}$ has been set to $333 \Omega$ and the rotational speed has reached $\Omega_{r}=1519 \mathrm{rpm}$. Given the excitation capacitor bank $(C=25 \mu \mathrm{F})$, the SEIG has been properly primed and the rms line voltage has reached $251 \mathrm{~V}$.

Under this generator condition, the value of the field current $I_{e x 0}$ is given by

$$
I_{e x 0}=\frac{U_{e x}}{R_{m}+R_{s h}+R_{0}}=218 \mathrm{~mA} .
$$

At the time $t_{d}=3.411 \mathrm{~s}$, we have actuate a push-button $\mathrm{K}$ to inset a resistance $R=18 \Omega$ is in series with $R_{0}$. Therefore, $I_{e x 0}$ has been decreased (Fig. 5) by an amount given by

$$
\frac{\Delta I_{e x}}{I_{e x 0}}=\frac{R}{R_{m}+R_{s h}+R_{0}+R}=1.93 \% .
$$

The rotational speed (rpm) for dc motors is given by

$$
\Omega=\frac{60 A}{p Z} \frac{E}{\phi}=\frac{E}{K \phi} .
$$

Where $p$ is the number of pair poles, $A$ the number of parallel paths, $Z$ the total active conductors in armature, $\phi$ the flux per pole, and $E$ is the motor back emf.

For a long shunt compound, the back emf can be expressed by

$$
E=U_{e x}-\left(R_{a}+R_{s}\right) I_{a} \text {. }
$$

Where $R_{a}$ is the total resistance of the motor armature, and $R_{s}$ the serial excitation winding.

On the other hand, in cumulative mode the total flux per pole is given by

$$
\phi=\phi_{s h}+\phi_{s}
$$

Neglecting saturation, and hysteresis phenomena, we can write

$$
\phi=\alpha I_{e x}+\beta I_{a} \text {. }
$$

where $(\alpha, \beta) \in^{\circ 2}$. Equation (17) gives

$$
\Omega=\frac{U_{e x}-\left(R_{a}+R_{s}\right) I_{a}}{K\left(\alpha I_{e x}+\beta I_{a}\right)} .
$$

For a constant load torque, the differentiation of Eq. (21) gives

$$
\Delta \Omega=\frac{-\alpha}{\left(\alpha I_{e x}+\beta I_{a}\right)} \Omega \Delta I_{e x} .
$$

Thus, the rotation speed will varies proportionally to the field current, but in an opposite way.

For each conducted test, we have readjusted the $R_{0}$ value order to secure a constant output frequency $\left(f_{s}=50 \mathrm{~Hz}\right)$. Identically the resistance $R$ has been properly regulated for guaranteeing the same relative variation of the dc motor excitation current.

The tests have been conducted on the SEIG under no-load condition as well as when it supplies various load levels $(300 \mathrm{~W}, 600 \mathrm{~W}, 900 \mathrm{~W}$, and $1 \mathrm{KW})$. Moreover, to study the effect of the load nature on the efficiency of the investigated approaches, two load natures have been considered: resistive, and with lagging power factor $(\mathrm{PF}=0.73 \mathrm{lag})$.

\section{A. IF estimation of the load current}

Figure 6 shows the raw IF data estimated by application of the HT to one-phase load current (HTLC). We observe that the estimated frequency is wandering into a range bounded by about 30 and $70 \mathrm{~Hz}$. Yet, the plot is marked by the attendance of many amplitude peaks.

Given these observations, the estimation of the IF derived from HTLC, is inefficient for detecting the moment of the defect occurrence.

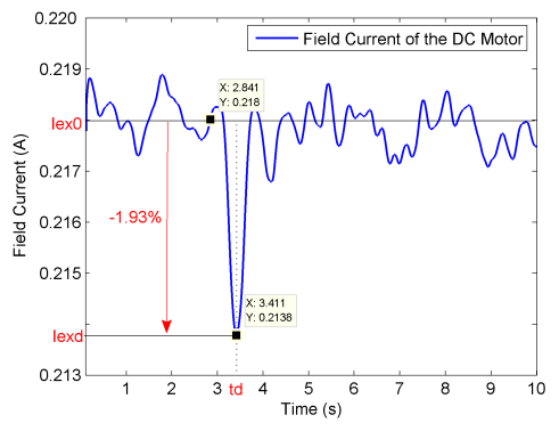

Fig. 5. Motor field current under no-load condition

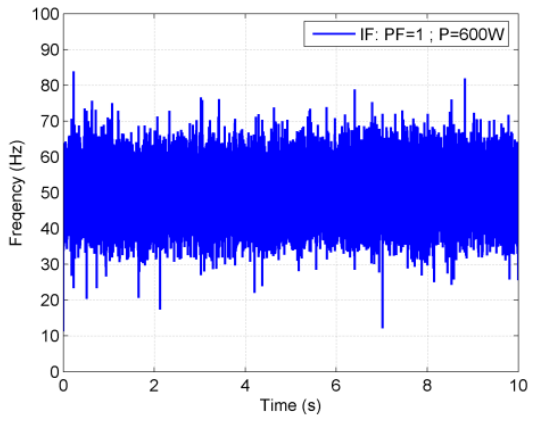

Fig. 6. Raw IF data estimated through HTLC. 
For efficiency enhancement, this technique is improved by adding a low-pass digital filter (Table 1: Filter B) acting on the original IF estimated previously. The resulting plot is given by Fig. 7. As it can be observed, the moment of speed boost is marked by a clear rise of the estimated frequency and the HTLC approach provides satisfying results in term of speed monitoring. Furthermore, the effectiveness of this approach has been proven for the two load conditions. Nevertheless, we note that the result obtained under lagging load condition is more stable in comparison with the case of resistive load.

\section{B. IF estimation of the stray flux}

Under resistive load condition, the estimation of the IF by suitable processing the transversal stray flux (PTSF) can provide the necessary information for perceiving the fault instant. However, a risk of false detection has been experienced. Indeed, an undesirable frequency peak has been observed far away of the speed boost occurrence (left plot of Fig. 8). This drawback was not observed when the generator supplies lagging loads (right plot of Fig. 8). Yet, the effectiveness of this monitoring approach has been proven even under no-load (Fig. 9).

\section{Discussion}

As it has been proven by the experimental results, the drive speed of a SEIG may be monitored through conventional processing of one-phase of the load current. Yet, the HTLC approach requires calling upon the HT, which cannot guarantee a physical meaning of frequency in many signal cases.

The proposed technique has the advantage to discard the need to access to the load line for picking the current. In addition, satisfactory results have been obtained by the use of low-cost sensors (simple search coil).

Obviously, the response speed related to each approach is a primary criterion for efficacy evaluation. Hence, for each conducted test we have prescribed in Table II the frequency peak moments obtained by the use of the two experienced techniques.
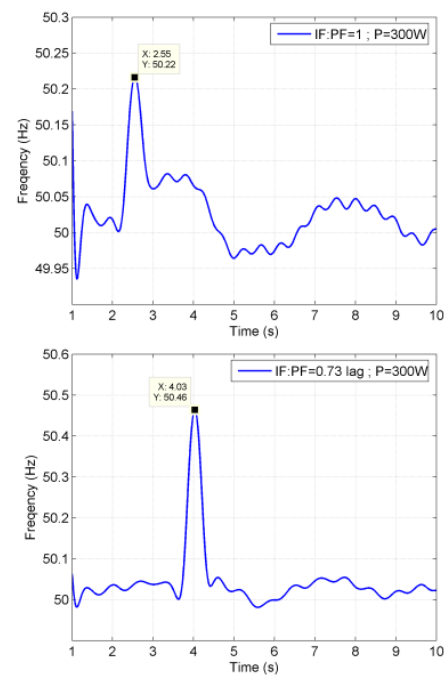

Fig. 7. IF estimation by HTLC, filtered data: resistive (left), lag (right) loads.

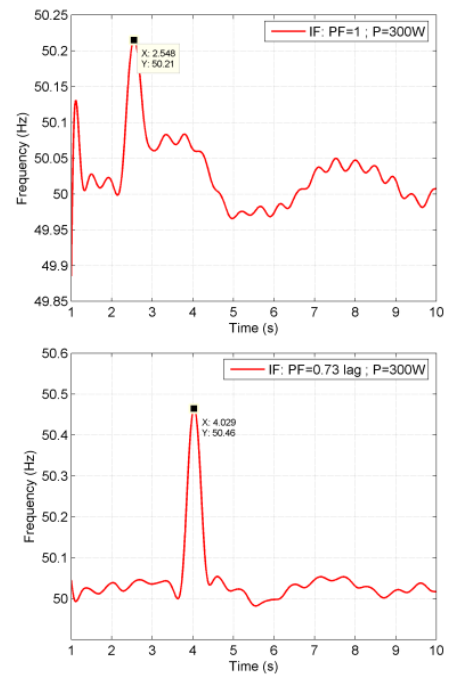

Fig. 8. IF estimation by PTSF: resistive (left), lag (right) loads.

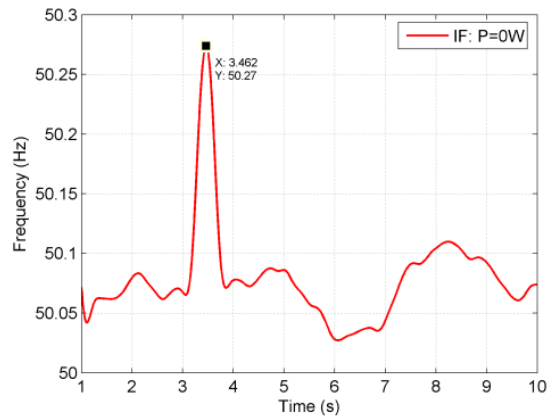

Fig. 9. IF estimation by PTSF: SEIG under no-load.

TABLE II. FREQUENCY PEAK MOMENTS UNDER VARIOUS LOAD CONDITIONS

\begin{tabular}{ccccc}
\hline \multirow{2}{*}{$\begin{array}{c}\text { Load } \\
\text { condition }\end{array}$} & $\boldsymbol{P}(\mathbf{W})$ & $\boldsymbol{I}_{\boldsymbol{e x}}(\mathbf{A})$ & \multicolumn{2}{c}{ Peak moments of speed boost (s) } \\
\cline { 3 - 5 } & & & $H T L C$ & $P T S F$ \\
\hline No-load & 0 & 3.411 & $\mathrm{x}$ & 3.462 \\
\hline Resistive & 300 & 2.448 & 2.550 & 2.548 \\
\cline { 2 - 5 } & 600 & 4.348 & 4.579 & 4.577 \\
\cline { 2 - 5 } & 900 & 3.279 & 3.353 & 3.346 \\
\cline { 2 - 5 } & 1000 & 3.065 & 3.082 & 3.077 \\
\hline Lagging 0.73 & 300 & 3.995 & 4.030 & 4.029 \\
\cline { 2 - 5 } & 600 & 3.239 & 3.286 & 3.286 \\
\cline { 2 - 5 } & 900 & 2.924 & 2.977 & 2.977 \\
\cline { 2 - 5 } & 1000 & 2.827 & 2.874 & 2.874 \\
\hline
\end{tabular}

As shown by table data, compared to the results provided by processing the load current, the proposed approach has shown excellent response time in detecting the speed boost, which is a critical defect in wind turbine applications.

\section{CONCLUSION}

In accordance with fundamental laws of electromagnetism, it is obvious that the generator's voltages giving rise to the flow of load currents are arising from the time derivative of the fluxes crossing the stator coils. Given this statement, any change, which could affect the normal operating condition of the generator will have initial effects on the embraced fluxes before spreading to affect main outputs. On the basis of this 
rationale, we have suggested an original approach to monitor the drive speed stability of a SEIG.

Compared to other conventional techniques, the main advantage of our technique is its easy and low-cost implementation. Indeed, the processed signal stems from a cheap noninvasive sensor, and there is no need to access the generator terminals. However, further efforts should be devoted for evaluating the accuracy, the robustness, and the limits of the proposed approach against noise and according to the fault severity.

\section{ACKNOWLEDGMENT}

The authors would like to thank A. Tlili and A. Barka for their help with the experimental setup.

\section{REFERENCES}

[1] D. Seyoum, C. Grantham, and M.F. Rahman, "The dynamic characteristics of an isolated self-excited induction generator driven by a wind turbine," IEEE Transaction on Industry Applications, vol. 39, n4, pp. 936-944, July-Aug. 2003.

[2] R. C. Bansal, "Three-phase self-excited induction generators: an overview," IEEE Transaction on Energy Conversion, vol. 20, n², pp. 292-299, June 2005.

[3] Y. Amirat, M.E.H. Benbouzid, E. Al-Ahmar, B. Bensaker, and S. Turri, "A brief status on condition monitoring and fault diagnosis in wind energy conversion systems," Renewable and Sustainable Energy Reviews, vol. 13, n9, pp. 2629-2636, December 2009.

[4] W. Yang, P.J. Tavner, and R. Court, "An online technique for condition monitoring the induction generators used in wind and marine turbines," Mechanical Systems and Signal Processing, vol. 38, n ${ }^{\circ}$, pp. 103-112 July 2013.

[5] F. P. G. Márquez, A. M. Tobias, J. M. P. Pérez, and M. Papaelias, "Condition monitoring of wind turbines: Techniques and methods," Renewable Energy, vol.46, n¹, pp. 169-178, October 2012.
[6] S.A. Deraz, and F.E. Abdel Kader, "A new control strategy for a standalone self-excited induction generator driven by a variable speed wind turbine," Renewable Energy, vol. 51, n¹, pp. 263-273, March 2013.

[7] M. Salah, K. Bacha, and A. Chaari, "Experimental technique for estimation of mechanical load unbalance level: Based on time analysis of induction machine stator current," in Proceedings of the 2013 ICEESA, Hammamet (Tunisia), pp. 1-6, March 2013.

[8] M. H. Haque, "Analysis of a self-excited induction generator with $\mathrm{P}-\mathrm{Q}$ load model,” IEEE Transaction on Energy Conversion, vol. 25, $\mathrm{n}^{\circ} 1$, pp. 265-267, March 2010.

[9] M.F. Ghazali, S.B.M. Beck, J.D. Shucksmith, J.B. Boxall, and W.J. Staszewski, "Comparative study of instantaneous frequency based methods for leak detection in pipeline networks," Mechanical Systems and Signal Processing, vol. 29, n ${ }^{\circ}$, pp. 187-200, May 2012.

[10] Y. Amirat, V. Choqueuse, M.E.H. Benbouzid and S. Turri, "Hilbert transform-based bearing failure detection in DFIG-based wind turbines," International Review of Electrical Engineering, vol. 6, n³, pp. 12491256, June 2011.

[11] B. Yang, and C. S. Suh, "Interpretation of crack-induced rotor nonlinear response using instantaneous frequency," Mechanical Systems and Signal Processing, vol. 18, n³, pp. 491-513, May 2004.

[12] Y. Amirat, V. Choqueuse and M.E.H. Benbouzid, "EEMD-based wind turbine bearing failure detection using the generator stator current homopolar component," Mechanical Systems and Signal Processing, vol. 41, n²1-2, pp. 667-678, December 2013.

[13] M. Salah, K. Bacha, and A. Chaari, "Comparative investigation of diagnosis media for induction machine mechanical unbalance fault," ISA Transactions, vol. 52, n ${ }^{\circ}$, pp. 888-899, November 2013.

[14] M. Salah, K. Bacha, and A. Chaari, "An improved spectral analysis of the stray flux component for the detection of air-gap irregularities in squirrel cage motors," ISA Transactions, vol. 53, n³, pp. 816-826, May 2014.

[15] M. Salah, K. Bacha, A. Chaari, and M.E.H. Benbouzid, "Brushless three-phase synchronous generator under rotating diode failure conditions," IEEE Transactions on Energy Conversion, vol. 29, n³, pp. 594-601, September 2014. 